\title{
Identifying clinical cases among patients assigned to psychoanalytic treatment
}

\author{
Caspar C. Berghout, MA \\ Jolien Zevalkink, PhD
}

The present study compared 89 patients assigned to long-term psychoanalytic psychotherapy or psychoanalysis in the Netherlands with psychiatric and nonclinical norm groups with regard to symptoms and personality pathology as assessed with six instruments. Patients filled in four self-report questionnaires (Symptom Checklist-90-Revised [SCL-90-R], Beck Depression Inventory-II [BDI-II], State-Trait Anxiety Inventory [STAI]) and underwent a personality assessment (Minnesota Multiphasic Personality Inventory-2 [MMPI-2], Rorschach-CS). The authors used statistically defined cutoff values for each measure. For each instrument separately, about $50 \%$ of the patients reported clinical levels of psychopathology, some patients being more depressed and others reporting other symptoms. By combining the test scores of the different instruments, the authors found that $91 \%$ of the patients were identified as clinical cases. Compared to psychiatric norm groups, these patients appeared to report lower levels of symptom distress, but similar levels of personality pathology. The next step will be to investigate the level of improvement after long-term psychoanalytic treatment. (Bulletin of the Menninger Clinic 72[4], 163-178)

Although several countries (e.g., Norway, Belgium, Germany, Canada, The Netherlands) provide government funding for long-term

\footnotetext{
The authors gratefully acknowledge Prof. Dr. J.V.T.M. de Jong, Free University Amsterdam, for comments on earlier versions of this article and to A.N.J. Pieters, Z. Saltzherr, and A. Beekhuyzen for coding the Rorschach protocols. This project was supported by the Netherlands ZonMw Grant 945-04-414. Dr. Berghout is psychologist and doctoral student at the Netherlands Psychoanalytic Institute, Amsterdam, The Netherlands. Dr. Zevalkink is psychologist and anthropologist and is head of the Department of Research and Quality Assurance at the Netherlands Psychoanalytic Institute, Amsterdam, The Netherlands.

Correspondence concerning this article should be addressed to C.C. Berghout, Department of Research and Quality Assurance, Netherlands Psychoanalytic Institute, PO Box 7031, 1007 JA Amsterdam, The Netherlands; e-mail: berghout@npsai.nl. (Copyright (C) 2008 The Menninger Foundation)
} 
ambulatory psychotherapy, such as psychoanalysis and psychoanalytic psychotherapy, not much is known about the characteristics of the patients assigned to these treatments. Do they resemble the general psychiatric population, or do they report psychopathology at a similar level as a nonclinical norm group? The present study aims to investigate whether patients assigned to long-term psychotherapy can be identified as clinical cases or not. In concordance with previous research (Derogatis \& Lazarus, 1994; Sandell et al., 2000), we calculated the proportion of patients whose test scores were above a statistically defined cutoff score on the different instruments to estimate the percentage of patients that are clinical cases. The answer to this research question might be relevant to researchers and policy makers, as well as clinicians.

First, researchers will know whether outcome studies into the effectiveness of long-term psychotherapy are feasible with the instruments selected for the current project. If the results of this study would show that these patients resemble patients in psychiatric care more than they resemble nonpatients, it would mean that the instruments apparently are sensitive enough to detect the mental health problems associated with this patient population and would therefore be useful in detecting improvements as a result of treatment. Second, policy makers will gain knowledge about the characteristics and distribution of illnesses of patients before psychoanalytic treatment, which they can use in order to provide more effective services (Howard et al., 1996).

Third, clinicians will get information and/or confirmation about the range of mental health characteristics they can expect from patients assigned to long-term ambulatory treatments (e.g., Health Council of the Netherlands, 2001). In the Netherlands, a routine outcome monitoring system was implemented to follow patients before and during psychoanalytic treatment (Zevalkink, 2004). The system included the Symptom Checklist-90-Revised (SCL90-R), Beck Depression Inventory-II (BDI-II), State-Trait Anxiety Inventory (STAI), Inventory of Interpersonal Problems-64 (IIP-64), Minnesota Multiphasic Personality Inventory-2 (MMPI-2), and the Rorschach inkblot test. ${ }^{1}$ We intended to determine where patients

1. The Adult Attachment Interview (AAI; George, Kaplan, \& Main, 1996) is included in the monitoring system as well, but results from this instrument are not available for this group of patients. 
applying for long-term psychoanalytic treatment would fit within the clinical spectrum of patients with mental health problems on the basis of these six instruments. The present study was a first step in a larger project of assessing the (cost-) effectiveness of long-term psychoanalytic psychotherapy and psychoanalysis in a naturalistic setting (Zevalkink \& Berghout, 2006).

Recent meta-analyses showed that psychoanalytic treatment proved to be an effective treatment for depression (Leichsenring, 2001) and personality disorders (Leichsenring \& Leibing, 2003). For the present study, we first conducted a systematic review of the research literature to investigate the results of other naturalistic studies on ambulatory psychoanalytic treatment that used similar instruments.

With regard to the symptom questionnaires, patients at onset of psychoanalytic treatment were found to score significantly higher on general symptomatology (SCL-90-R), depression (BDIII), anxiety (STAI), and interpersonal problems (IIP-64) compared to nonclinical norm groups, though not all patients had clinically elevated scores on all instruments (Finland: Knekt \& Lindfors, 2004; Germany: Brockman, Schlüter, Brodbeck, \& Eckert, 2002; Leichsenring, Biskup, Kreische, \& Staats, 2005; Puschner, Kraft, \& Bauer, 2004; Sweden: Blomberg, Lazar, \& Sandell, 2001; Sandell et al., 2000; United States: Vaughan et al., 2000).

Next, for each of the six instruments the number of clinical cases in the norm groups--as reported in the manuals--was examined. This confirmed that not every patient in the psychiatric norm group could be identified as a clinical case. For example, the percentage of psychiatric patients with a clinically elevated mean score (calculated according to Sandell et al., 2000) on the BDI-II appeared to be $69 \%$ (van der Does, 2002), and on the STAI (Trait score) $48 \%$ of the psychiatric patients scored above the clinical cutoff (van der Ploeg, 2000).

Relatively few studies using the MMPI-2 have been done with patients in psychoanalytic treatment. In the United States, Gordon (2001) administered the MMPI to outpatients receiving long-term psychoanalytic psychotherapy. He showed that patients at onset of treatment scored within the clinical range on several scales and started to change significantly after 2 years of treatment (Gordon, 2001). Studies on the Rorschach showed that patients at onset of 
ambulatory psychoanalytic treatment had clinically elevated mean scores on most of the selected Comprehensive System indices of adjustment difficulty, and thus fulfilled the clinical criteria of maladjustment (Knekt \& Lindfors, 2004; Weiner \& Exner, 1991). With regard to the Special Indices of the Rorschach, Weiner and Exner (1991) studied two indices and found that $32 \%$ of their patients had an elevated Coping Deficit Index (CDI > 3) and 60\% had an elevated Depression Index (DEPI $>4$ ). We expected patients applying for psychoanalytic treatment in the Netherlands to show similar patterns.

Patients assigned to long-term psychoanalytic treatment ("intention-to-treat") were compared with two reference groups, one consisting of patients in regular clinical practice and the other of nonclinical subjects. For this comparison, we used standardized means as reported in each of the instrument's manuals to constitute the two reference groups. The data in these manuals consists of established, up-to-date, and reliable reference groups. Furthermore, we examined whether or not our patients could be identified as clinical cases according to specific criteria. In this, we followed other researchers who had shown that it is possible to use statistically defined cutoff values and combine different instruments to come to a global assessment of the percentage of clinical cases in a certain patient population (Blomberg et al., 2001; Puschner, Kraft, Kächele, \& Kordy, 2007; Sandell et al., 2000).

\section{Method}

\section{Subjects}

The total sample consisted of 89 subjects ( $76 \%$ female) who were indicated for long-term ambulatory psychoanalytic treatment. The mean age at intake was 30.8 years $(\mathrm{SD}=7.1$; range $18-48)$. Of this group, $31 \%$ had a spouse and $16 \%$ had children. The majority of patients was employed $(78 \%)$ and had received higher education $(76 \%)$. Eleven percent had a non-Western cultural background. With regard to treatment history, we found that $65 \%$ of our patients had received previous (psychotherapeutic) treatment before applying for long-term psychoanalytic treatment. Most commonly diagnosed DSM-IV-TR disorders were: mood disorders $(51 \%$; in 
Identifying Clinical Cases

particular dysthymia $35 \%)$, anxiety disorders $(18 \%)$, and adjustment disorders $(8 \%)$, where $18 \%$ were diagnosed with more than one Axis I disorder. Seventy-four percent of the patients was diagnosed with an additional V-code, of which identity problems and relational problems were most common. Twenty percent of the patients was diagnosed with no Axis I disorder, only a V-code. Due to administrative problems, no systematic data were available with regard to Axis II disorders. The average GAF score was 59.9 (SD $=8.8)$.

\section{Procedure}

All patients who applied for treatment between June 2002 and November 2004 at a community mental health clinic specialized in long-term ambulatory psychoanalytic treatment were asked to fill in four self-report questionnaires (SCL-90-R, BDI-II, STAI, and IIP-64). After this, a personality assessment was carried out consisting of the MMPI-2 and the Rorschach inkblot test. The administration and scoring of the Rorschach were done by well-trained psychologists according to the Comprehensive System (Exner, 2001, 2003). In total, 89 patients who participated in the personality assessment received an indication for long-term psychoanalytic treatment at our facility. Rorschach and MMPI-2 data for all patients were complete. However, for 4 patients the data of the screening questionnaires were not complete.

\section{Measures}

Symptom questionnaires. In the Netherlands, norms and translation of the SCL-90-R were developed by Arrindell and Ettema (2003). The Global Severity Index (GSI) gives an indication of the general symptomatology. The BDI-II measures depressive symptoms, and van der Does (2002) developed norm scores in the Netherlands. The IIP-64 is used to systematically examine different types of interpersonal problems (Horowitz, Alden, Wiggins, \& Pincus, 2000). The translation and norm scores of the STAI were developed by van der Ploeg (2000).

Personality assessment. The MMPI-2 aims to give a quantitative measurement of the individual's level of emotional adjustment 
and attitude toward test taking, resulting in clusters of personality variables (Groth-Marnat, 1997). In concordance with other research, we used eight clinical scales, because scales 5-Masculinity-Femininity (Mf) and 0-Social Introversion (Si) are usually not considered as clinical scales (Nieberding et al., 2003; Terlidou et al., 2004). Derksen, de Mey, Sloore, and Hellenbosch (2006) translated the MMPI-2 and developed norms for use in the Netherlands. The relatively new Personality Psychopathology Five (PSY-5) scales were also included: Aggressiveness, Psychoticism, Disconstraint, Negative Emotionality/Neuroticism, and Introversion/Low Positive Emotionality (Harkness \& McNulty, 2006). The Rorschach is useful for predicting and evaluating outcome and provides an assessment of someone's personality structure and dynamics (Groth-Marnat, 1997; Viglione, 1999). In this study, we used the six Special Indices: Perceptual-Thinking, Depression, Coping Deficit, Suicide Constellation, Hypervigilance, and Obsessive Style. Norm scores were derived from Exner (2001). We included scores on the Ego Impairment Index-2 (EII-2), which is a relatively new Rorschach composite. The EII-2 measures psychological impairment and thought disturbance (Viglione, Perry, \& Meyer, 2003). For descriptive purposes, we also examined the emotional coping style (EB). The EB gives an indication of a person's predominant emotional coping style: ambitent (varied use of external and internal resources), extratensive (mostly use external resources for gratification of basic needs), introversive (mostly use inner life for satisfaction of important needs), or avoidant (tend to minimize the importance of the stimulus field) (Exner, 2003). On the emotional coping style (EB) we found the following results: $44 \%$ ambitent, $12 \%$ extratensive, $35 \%$ introversive, and $9 \%$ avoidant.

\section{Statistical analyses}

Comparison with nonclinical and psychiatric norm groups. We examined differences and similarities by comparing test scores of our patients with those of the psychiatric reference groups and nonclinical norm groups that are mentioned in the manuals of the different instruments (t-test, chi-square).

Criterion for clinical case. To estimate the percentage of patients that could be identified as clinical cases, we calculated the propor- 
Identifying Clinical Cases

Table 1. Means and standard deviations on the four symptom questionnaires and comparisons with psychiatric and nonclinical norm groups

\begin{tabular}{|c|c|c|c|c|c|c|c|c|}
\hline \multirow[b]{3}{*}{ Questionnaire } & \multicolumn{6}{|c|}{ Group } & \multicolumn{2}{|c|}{ Comparison } \\
\hline & \multicolumn{2}{|c|}{1} & \multicolumn{2}{|c|}{2} & \multicolumn{2}{|c|}{3} & \multirow{2}{*}{$\frac{1 \text { vs. } 2}{t}$} & \multirow{2}{*}{$\frac{1 \text { vs. } 3}{t}$} \\
\hline & M & $(S D)$ & $M$ & $(S D)$ & $M$ & $(S D)$ & & \\
\hline $\begin{array}{l}\text { SCL-90-R GSI } \\
\text { score }\end{array}$ & 0.98 & $(0.50)$ & 1.26 & $(0.68)$ & 0.31 & $(0.36)$ & $-5.19 * * *$ & $12.42 * * *$ \\
\hline $\begin{array}{l}\text { BDI-II Total } \\
\text { score }\end{array}$ & 17.9 & $(8.5)$ & 21.4 & $(12.2)$ & 6.2 & (6.2) & $-2.96^{* * *}$ & $12.27 * * *$ \\
\hline $\begin{array}{l}\text { IIP-64 Total } \\
\text { score }\end{array}$ & 92.0 & $(30.3)$ & 112.2 & $(34.2)$ & 51.5 & $(34.3)$ & $-5.65 * *$ & $11.58 * *$ \\
\hline $\begin{array}{c}\text { STAI Trait } \\
\text { score }\end{array}$ & 52.9 & $(9.0)$ & 51.6 & $(11.6)$ & 38.4 & (10.8) & 0.92 & $12.99 * * *$ \\
\hline
\end{tabular}

Note. Group 1 = Patients before psychoanalytic treatment $(N=85-87)$; Group 2 = Psychiatric norm group; Group $3=$ Nonclinical norm group. Data from the psychiatric and nonclinical norm group for the SCL-90-R were derived from Arrindell and Ettema (2003); BDI-II: van der Does (2002); IIP-64: Horowitz, Aldern, Wiggins, \& Pincus (2000); and STAI: van der Ploeg $(2000) . * *<.01 ; * * *<.001$.

tion of patients whose test scores were located above a statistically defined cutoff score on the different instruments. In concordance with previous research (Derogatis \& Lazarus, 1994; Sandell et al., 2000 ), we used the value that divides the $10 \%$ worst scoring persons in the nonclinical norm group from the $90 \%$ best scoring persons. This division corresponds to 1.28 standard deviation above the mean in a normal distribution. The overall criterion for clinical case was established as patients with scores within the clinical range on at least two of the screening questionnaires and/or two clinical scales of the MMPI-2 and/or two of the Rorschach Special Indices.

Results

\section{Symptom questionnaires: Comparisons with nonclinical and psychiatric norm groups}

Table 1 shows the mean scores and standard deviations on the four questionnaires. Our patient group scored significantly higher (i.e., more complaints/problems) on all questionnaires in comparison to the nonclinical norm groups. Subscale scores are not mentioned in Table 1, but without exception they were all significantly higher in our patient group compared to the nonclinical norm groups. Table 
Berghout and Zevalkink

Table 2. Means and standard deviations on the clinical scales of the Minnesota Multiphasic Personality Inventory-2 and comparisons with psychiatric and nonclinical norm groups

\begin{tabular}{|c|c|c|c|c|c|c|c|c|}
\hline \multirow[t]{3}{*}{ MMPI-2 scale } & \multicolumn{6}{|c|}{ Group } & \multicolumn{2}{|c|}{ Comparison } \\
\hline & \multicolumn{2}{|c|}{1} & \multicolumn{2}{|c|}{2} & \multicolumn{2}{|c|}{3} & \multirow{2}{*}{$\frac{1 \text { vs. } 2}{\mathrm{t}}$} & \multirow{2}{*}{$\frac{1 \text { vs. } 3}{t}$} \\
\hline & M & $(S D)$ & $M$ & $(S D)$ & $M$ & $(S D)$ & & \\
\hline 1-Hypochondriasis & 55.8 & $(10.9)$ & 61.6 & $(5.9)$ & 50 & $(10)$ & $-4.39 * * *$ & $4.86^{* * *}$ \\
\hline 2-Depression & 62.9 & $(12.7)$ & 67.9 & $(11.6)$ & 50 & $(10)$ & $-2.66^{* *}$ & $9.39 * * *$ \\
\hline 3-Hysteria & 61.0 & $(13.0)$ & 66.9 & $(9.3)$ & 50 & $(10)$ & $-3.41^{* * *}$ & $7.84 * * *$ \\
\hline $\begin{array}{c}\text { 4-Psychopathic } \\
\text { deviate }\end{array}$ & 67.1 & $(10.8)$ & 66.2 & $(9.8)$ & 50 & $(10)$ & 0.53 & $14.49 * * *$ \\
\hline 6-Paranoia & 61.5 & $(11.7)$ & 65.4 & $(10.5)$ & 50 & $(10)$ & $-2.27 *$ & $9.10 * * *$ \\
\hline 7-Psychasthenia & 67.0 & $(12.5)$ & 66.2 & $(8.8)$ & 50 & $(10)$ & 0.49 & $12.58 * *$ \\
\hline 8-Schizophrenia & 63.4 & $(10.8)$ & 69.1 & $(13.0)$ & 50 & $(10)$ & $-3.11^{* *}$ & $11.38 * * *$ \\
\hline 9-Hypomania & 52.0 & $(11.0)$ & 62.5 & (8.3) & 50 & $(10)$ & $-7.03 * * *$ & 1.70 \\
\hline
\end{tabular}

Note. Group 1 = Patients before psychoanalytic treatment $(N=89)$; Group $2=$ Psychiatric norm group; Group 3 = Nonclinical norm group. Data from the psychiatric and nonclinical norm group were derived from Derksen, de Mey, Sloore \& Hellenbosch (2006). * $p<.05 ;{ }^{* *} p<$ $.01 ; * * p<.001$.

1 also shows that our patients scored significantly lower than other psychiatric norm groups regarding general symptomatology (SCL90-R), depression (BDI-II), and interpersonal problems (IIP-64). On trait anxiety (STAI Trait) there was no significant difference between our patients and the psychiatric norm group.

\section{Personality assessment: Comparisons with nonclinical and psychiatric norm groups}

Table 2 shows the mean scores and standard deviations on the clinical scales of the MMPI-2. On all MMPI-2 clinical scales except scale 9-Hypomania, patients applying for psychoanalytic treatment scored significantly higher than the nonclinical norm group. However, comparisons with the psychiatric norm group showed that our patients scored significantly lower on scales 1 - Hypochondriasis, 2-Depression, 3-Hysteria, 6-Paranoia, 8-Schizophrenia, and 9-Hypomania. No differences were found on the other clinical scales. We also investigated the percentage of patients who had clinically elevated scores on the PSY-5 variables. We found no significant de- 
Identifying Clinical Cases

Table 3. Percentage of patients with clinically elevated scores on the six Rorschach Special Indices in comparison to clinical and nonclinical reference groups

\begin{tabular}{|c|c|c|c|c|c|}
\hline \multirow[b]{3}{*}{ Special Indices } & \multicolumn{3}{|c|}{ Group } & \multicolumn{2}{|c|}{ Comparison } \\
\hline & 1 & 2 & 3 & 1 vs. 2 & 1 vs. 3 \\
\hline & $\%$ & $\%$ & $\%$ & $\chi^{2}$ & $\chi^{2}$ \\
\hline Perceptual-Thinking (PTI > 2) & 15 & 2 & 0 & $28.3 * * *$ & $74.1 \% * a$ \\
\hline Depression (DEPI > 4) & 53 & 20 & 5 & $43.5 * *$ & $178.5^{* * *}$ \\
\hline Coping Deficit $(\mathrm{CDI}>3)$ & 25 & 31 & 4 & 1.4 & $55.4 * * *$ \\
\hline Suicide Constellation $(\mathrm{S}-\mathrm{CON}>7$ ) & 7 & 0 & 0 & $23.9 * * * a$ & $33.4^{* * * a}$ \\
\hline Hypervigilance (HVI Positive) & 26 & 11 & 3 & $13.7 * * *$ & $72.3 * * *$ \\
\hline Obsessive Style (OBS Positive) & 1 & 8 & 1 & $4.7^{* a}$ & $0.1^{\mathrm{a}}$ \\
\hline
\end{tabular}

Note. Group 1 = Patients before psychoanalytic treatment $(N=89)$; Group 2 = Psychiatric norm group; Group 3 = Nonclinical norm group. Data from the psychiatric and nonclinical norm group were derived from Exner (2001). ${ }^{a} \chi^{2}$ with Yates correction. ${ }^{*} p<.05 ;{ }^{* * *} p<.001$.

viations from the percentages in the nonclinical reference group on the first three variables, but on the scale for Negative Emotionality/ Neuroticism $38 \%$ had an elevated score and on Introversion/Low Positive Emotionality 39\% scored within the clinical range.

Table 3 shows the percentage of patients with clinically elevated scores on the Special Indices of the Rorschach. On all Special Indices except the Obsessive Style Index, significantly more of our patients appeared to have clinically elevated scores in comparison to the nonclinical norm group. Comparisons with the psychiatric norm group showed that in our patient group, significantly fewer patients had a clinically elevated score on the Obsessive Style Index. However, on the Perceptual-Thinking Index, Depression Index, Suicide Constellation, and Hypervigilance Index, our patient group had significantly more clinically elevated scores than the psychiatric norm group. No significant difference was found on the Coping Deficit Index. Next, we analyzed Ego Impairment Index-2 scores. We found that $47 \%$ of the patients had high scores, indicating moderate to severe impairment (EII-2 > 0.7). More than half of these patients even had significant impairment $($ EII-2 $>1.3)$.

\section{Combining instruments: Clinical cases across instruments}

We first combined the test scores from the four symptom questionnaires and calculated the percentages of patients who scored within 
the clinical range on SCL-90-R GSI score, BDI-II Total score, STAI Trait score, or IIP-64 Total score. We found that $60 \%$ of our patients had clinically elevated scores on at least two questionnaires. To be more specific, $16 \%$ scored within the clinical range on two questionnaires, $18 \%$ on three questionnaires, and $26 \%$ on all four symptom questionnaires. Then we combined the test scores from the two personality assessment instruments and looked at the percentage of patients who had clinically elevated scores on either the MMPI-2 (at least two clinical scales) or the Rorschach (at least two Special Indices). We found that $85 \%$ of our patients met these criteria. More specifically, $50 \%$ of the patients had clinically elevated scores on the MMPI- 2 but not on the Rorschach; $9 \%$ of the patients scored clinically elevated on the Rorschach but not on the MMPI-2; and $26 \%$ of the patients had clinically elevated scores on both the MMPI-2 and the Rorschach. Finally, we combined the results from the symptom questionnaires with the personality assessment instruments. A clinical case was defined as someone who scored within the clinical range on at least two symptom questionnaires and/or at least two MMPI-2 clinical scales and/or at least two Rorschach Special Indices. On these criteria, 91\% of the patients assigned to long-term psychoanalytic treatment were identified as clinical cases.

\section{Discussion}

In the present study we gave a description of patients assigned to long-term ambulatory psychoanalytic treatment in the Netherlands on the basis of six instruments. Four screening questionnaires and two personality assessment instruments were used. Compared to psychiatric norm groups, our patients appeared to report lower levels of symptom distress, whereas with regard to personality problems our patients presented similar levels of psychopathology. Patients assigned to long-term psychoanalytic treatment were characterized by high levels of depression, hypervigilance, trait anxiety, and problems in reality testing. In addition, we found that most of these patients had an introversive style of coping with emotional difficulties or made varied use of external and internal resources. This particular personality pathology in combination with the high 
prevalence of (chronic) mood disorders shows that this patient population occupies its own niche within mental health care. For clinicians, it is important to identify the particulars of this patient group, so that better decisions can be made regarding treatment assignment. This concerns patients who seemingly have few symptoms or complaints and can therefore function reasonably well in certain areas of life, but nonetheless suffer from high levels of hidden distress and personality problems for which they seek help. Scores on the Rorschach EII-2, for example, suggest that problemsolving failures or ineffective and idiosyncratic thinking in complex and demanding life situations were very common in our patient sample. These problems exist on a deeper personality level, which seem hard to capture with short self-report questionnaires. The PSY-5 scales of the MMPI-2 showed that many patients assigned to psychoanalytic treatment had a tendency to focus on problematic aspects of experiences/stimuli, or, in other words, to worry about and anticipate the "worst case scenario." Moreover, many of these persons seem to have developed an introvert style of dealing with emotional problems as a result of early life experiences. These results are in concordance with those of other studies on patients before psychoanalytic treatment (Blatt \& Shahar, 2004; Fonagy et al., 1996; Holmes, 2001; Horowitz, Rosenberg, \& Bartholomew, 1993; Levy et al., 2006). The results of these studies suggested that patients with an avoidant attachment style and patients with "introjective" psychopathology might improve significantly more after a high-frequency and long-term treatment in contrast to a low-frequency and short-term treatment.

As reported elsewhere, the clinicians' assignment to long-term treatments seems to be in line with the research findings (e.g., Zevalkink \& Berghout, 2008). Perhaps the stereotype of psychoanalytic treatment being for the "worried well" is based on the observation that these patients report fewer symptoms in comparison with other psychotherapy patients. With the aid of personality assessments, however, the current study shows that the majority of these patients were in fact clinical cases, although in less easily detectable areas of social and emotional functioning. In line with other researchers, we suggest that long-term treatments are especially well suited for patients with personality disorders and/or recurrent or chronic depression, because of the complexity of the underlying 
problems (Bateman \& Fonagy, 1999; Doidge et al., 2002; Perry, Banon, \& Ianni, 1999).

Some limitations can be noted with regard to the generalizability of our results. First, with regard to sociodemographic characteristics, results were comparable with those in other studies of patients assigned to psychoanalytic treatment: mainly women, highly educated, and without a spouse (e.g., Sandell et al., 2000). We could not compare this with characteristics of patients in the reference groups, because these data were not mentioned in the manuals of the instruments. Results from Olfson and Pincus (1994) did show that long-term psychotherapy users tended to have a higher education than either short-term psychotherapy users or those who did not use psychotherapy. Therefore, the generalizability of these results might apply only to patients assigned to long-term treatment. Second, the generalizability depends on the quality of the instruments. We selected instruments with good psychometric properties. Most controversial in our test battery is the Rorschach inkblot test. The Rorschach, scored according to the Comprehensive System, has good psychometric qualities (Exner, 2003; Meyer \& Archer, 2001) but has not yet been researched extensively in the Netherlands (Evers, van Vliet-Mulder, \& Groot, 2000). Therefore, our results may have a bias with norm groups outside the Netherlands. More normative research is needed for the Rorschach in the Netherlands so that differences and similarities with other psychotherapy patients can be identified more accurately. Third, the definition of a clinical case is crucial in this discussion. In this, we followed other studies (Blomberg et al., 2001; Derogatis \& Lazarus, 1994; Puschner et al., 2007; Sandell et al., 2000) and tried to make an even more conservative estimate of the number of clinical cases. This was done by adding the criteria that a person would be considered a clinical case if this shows on several symptom questionnaires and/or several MMPI-2 clinical scales and/or several Rorschach Special Indices. For instance, a person who had a clinically elevated score on just one of the questionnaires (e.g., BDI-II), one MMPI-2 clinical scale (e.g., scale 2-Depression), and only one of the Special Indices (e.g., DEPI) would not be considered a clinical case according to our criteria. In our sample, this was the case for $9 \%$ of our patients. This number is in agreement with other 
research findings showing that approximately $15 \%$ of patients in ambulatory treatment report functioning in the nonclinical range on standardized tests at intake (Lambert, Okiishi, Finch, \& Johnson, 1998). This, however, does not necessarily mean that these patients do not have substantial problems. It can also indicate that these patients' problems are very hard to detect, even with wellestablished assessment instruments. Further research is needed to find out if this tighter definition of a clinical case will be useful. Finally, no data on outcome are available yet. The next step is to investigate whether long-term psychoanalytic treatment is effective in reducing the number of clinical cases and realizing stable improvements in a person's emotional and social functioning. What we do know is that personality instruments play a crucial role in detecting clinical cases in this particular patient niche.

\section{References}

Arrindell, W.A., \& Ettema, J.H.M. (2003). Symptom Checklist: Handleiding bij een multidimensionele psychopathologie-indicator [Symptom Checklist: Manual of the multidimensional indicator of psychopathology]. Lisse: Swets Test Publisher.

Bateman, A., \& Fonagy, P. (1999). Effectiveness of partial hospitalization in the treatment of borderline personality disorder: A randomized controlled trial. American Journal of Psychiatry, 156, 1563-1569.

Blatt, S.J., \& Shahar, G. (2004). Psychoanalysis-With whom, for what, and how? Comparisons with psychotherapy. Journal of the American Psychoanalytic Association, 52, 393-448.

Blomberg, J., Lazar, A., \& Sandell, R. (2001). Long-term outcome of long-term psychoanalytically oriented therapies: First findings of the Stockholm Outcome of Psychotherapy and Psychoanalysis study. Psychotherapy Research, 11, 361-382.

Brockmann, J., Schlüter, T., Brodbeck, D., \& Eckert, J. (2002). Die effekte psychoanalytisch orientierter und verhaltenstherapeutischer langzeittherapien [Effects of psychoanalytically oriented and of behavioral long-term therapies]. Psychotherapeut, 47, 347-355.

Derksen, J.J.L., de Mey, H.R.A., Sloore, H., \& Hellenbosch, G. (2006). MMPI-2: Handleiding voor afname, scoring en interpretatie [MMPI-2: Manual for administration, scoring and interpretation]. Nijmegen: Pen Psychodiagnostics.

Derogatis, L.R., \& Lazarus, L. (1994). SCL-90-R, Brief Symptom Inventory, and matching clinical rating scales. In M.E. Maruish (Ed.), The use of psychological testing for treatment planning and outcome assessment (pp. 217-248). Hillsdale, NJ: Lawrence Erlbaum. 
van der Does, A.J.W. (2002). BDI-II-NL: Handleiding Beck Depression Inventory-II, Nederlandse vertaling en bewerking [BDI-II-NL: Manual Beck Depression Inventory-II, Dutch translation and adaptation]. Lisse: Swets Test Publisher.

Doidge, N., Simon, B., Brauer, L., Grant, D.C., First, M., Brunshaw, J. et al. (2002). Psychoanalytic patients in the U.S., Canada, and Australia: 1. DSMIII-R disorders, indications, previous treatment, medications, and length of treatment. Journal of the American Psychoanalytic Association, 50, 575-614.

Evers, A., van Vliet-Mulder, J.C., \& Groot, C.J. (2000). Documentatie van tests en testresearch in Nederland [Documentation of tests and test research in the Netherlands]. Assen: Van Gorcum; Amsterdam: Nederlands Instituut voor Psychologen (NIP).

Exner, J.E. (2001). A Rorschach workbook for the Comprehensive System. Asheville, NC: Rorschach Workshops.

Exner, J.E. (2003). The Rorschach: A Comprehensive System (4th ed.). Hoboken, NJ: John Wiley \& Sons, Inc.

Fonagy, P., Leigh, T., Steele, M., Steele, H., Kennedy, R., Mattoon, G., et al. (1996). The relation of attachment status, psychiatric classification, and response to psychotherapy. Journal of Consulting and Clinical Psychology, 64, 22-31.

George, C., Kaplan, N., \& Main, M. (1996). Adult Attachment Interview (3 ${ }^{\text {rd }}$ ed.). Berkeley, CA: Department of Psychology, University of California.

Gordon, R.M. (2001). MMPI/MMPI-2 changes in long-term psychoanalytic psychotherapy. Issues in Psychoanalytic Psychotherapy, 23, 59-79.

Groth-Marnat, G. (1997). Handbook of psychological assessment. Hoboken, NJ: John Wiley \& Sons, Inc.

Harkness, A.R., \& McNulty, J.L. (2006). An overview of personality: The MMPI-2 Personality Psychopathology Five Scales. In J.N. Butcher (Ed.), MMPI-2: A practitioner's guide (pp. 73-97). Washington, DC: American Psychological Association.

Health Council of the Netherlands (2001). The efficiency of long-term psychotherapy. The Hague: Health Council of the Netherlands, 2001/8E.

Holmes, J. (2001). The search for the secure base: Attachment theory and psychotherapy. Hove: Brunner-Routledge.

Horowitz, L.M., Alden, L.E., Wiggins, J.S., \& Pincus, A.L. (2000). Inventory of Interpersonal Problems: Manual. New York: The Psychological Corporation Harcourt.

Horowitz, L.M., Rosenberg, S.E., \& Bartholomew, K. (1993). Interpersonal problems, attachment styles, and outcome in brief dynamic psychotherapy. Journal of Consulting and Clinical Psychology, 61, 549-560.

Howard, K.I., Cornille, T.A., Lyons, J.S., Vessey, J.T., Lueger, R.J., \& Saunders, S.M. (1996). Patterns of mental health service utilization. Archives of General Psychiatry, 53, 696-703.

Knekt, P., \& Lindfors, O. (2004). A randomized trial of the effect of four forms of psychotherapy on depressive and anxiety disorders: Design, methods, and results on the effectiveness of short-term psychodynamic psychotherapy and solution-focused therapy during a one-year follow-up. Helsinki: Edita. 
Lambert, M.J., Okiishi, J.C., Finch, A.E., \& Johnson, L.D. (1998). Outcome assessment: From conceptualization to implementation. Professional Psychology: Research and Practice, 29, 63-70.

Leichsenring, F. (2001). Comparative effects of short-term psychodynamic therapy and cognitive-behavioral therapy in depression: A meta-analysis. Clinical Psychology Review, 21, 401-419.

Leichsenring, F., Biskup, J., Kreische, R., \& Staats, H. (2005). The Göttingen study of psychoanalytic therapy: First results. International Journal of Psychoanalysis, 86, 433-455.

Leichsenring, F., \& Leibing, E. (2003). The effectiveness of psychodynamic therapy and cognitive behavior therapy in the treatment of personality disorders: A meta-analysis. American Journal of Psychiatry, 160, 1223-1232.

Levy, K.N., Meehan, K.B., Kelly, K.M., Reynoso, J.S., Weber, M., Clarkin, J.F., et al. (2006). Change in attachment patterns and reflective function in a randomized control trial of transference-focused psychotherapy for borderline personality disorder. Journal of Consulting and Clinical Psychology, 74, 1027-1040.

Meyer, G.J., \& Archer, R.P. (2001). The hard science of Rorschach research: What do we know and where do we go? Psychological Assessment, 13, 486-502.

Nieberding, R.J., Gacono, B.B., Pirie, M., Bannatyne, L.A., Viglione, D.J., Cooper, B., et al. (2003). MMPI-2 based classification of forensic psychiatric outpatients: An exploratory cluster analytic study. Journal of Clinical Psychology, 59, 907-920.

Olfson, M., \& Pincus, H.A. (1994). Outpatient psychotherapy in the United States, II: Patterns of utilization. American Journal of Psychiatry, 151, 1289-1294.

Perry, J.C., Banon, E., \& Ianni, F. (1999). Effectiveness of psychotherapy for personality disorders. American Journal of Psychiatry, 156, 1312-1321.

Ploeg, H.M., van der (2000). Handleiding bij de Zelf BeoordelingsVragenlijst: Een Nederlandstalige bewerking van de Spielberger State-Trait Anxiety Inventory [Manual of the State-Trait Anxiety Inventory: A Dutch translation of the Spielberger State-Trait Anxiety Inventory]. Lisse: Swets Test Publisher.

Puschner, B., Kraft, S., \& Bauer, S. (2004). Interpersonal problems and outcome in outpatient psychotherapy: Findings from a long-term longitudinal study in Germany. Journal of Personality Assessment, 83, 223-234.

Puschner, B., Kraft, S., Kächele, H., \& Kordy, H. (2007). Course of improvement during two years in psychoanalytic and psychodynamic outpatient psychotherapy. Psychology and Psychotherapy, 80, 51-68.

Sandell, R., Blomberg, J., Lazar, A., Carlsson, J., Broberg, J., \& Schubert, J. (2000). Varieties of long-term outcome among patients in psychoanalysis and long-term psychotherapy. International Journal of Psychoanalysis, 81, 921-942.

Terlidou, C., Moschonas, D., Kakitsis, P., Manthouli, M., Moschona, T., \& Tsegos, I.K. (2004). Personality changes after completion of long-term groupanalytic psychotherapy. Group Analysis, 37, 401-418. 
Vaughan, S.C., Marshall, R.D., MacKinnon, R.A., Vaughan, R., Mellman, L., \& Roose, S.P. (2000). Can we do psychoanalytic outcome research? A feasibility study. International Journal of Psychoanalysis, 81, 513-527.

Viglione, D.J. (1999). A review of recent research addressing the utility of the Rorschach. Psychological Assessment, 11, 251-265.

Viglione, D.J., Perry, W., \& Meyer, G.J. (2003). Refinements in the Rorschach Ego Impairment Index incorporating the Human Representational Variable. Journal of Personality Assessment, 81, 149-156.

Weiner, I.B., \& Exner, J.E. (1991). Rorschach changes in long-term and shortterm psychotherapy. Journal of Personality Assessment, 56, 453-465.

Zevalkink, J. (2004). Indicatie- en behandelingsprotocol voor volwassenen [Protocol for treatment assignment and treatment progress in adult patients]. Amsterdam: Netherlands Psychoanalytic Institute.

Zevalkink, K. \& Berghout, C. C. (2006). Expanding the evidence base for the cost-effectiveness of long-term psychoanalytic treatment. Journal of the American Psychoanalytic Association, 54, 1313-1319.

Zevalkink, K. \& Berghout, C. C. (2008). Mental health characteristics of patients assigned to long-term ambulatory psychoanalytic psychotherapy and psychoanalysis in the Netherlands. Psychotherapy Research, 18, 316-325. 